\title{
Wpływ wybranych parametrów spawania łukowego na jakość złączy odlewniczych stopów magnezu
}

\section{Influence of arc welding parameters on joints quality of cast magnesium alloys}

\section{Streszczenie}

W artykule przedstawiono wpływ wybranych parametrów spawania łukowego na jakość złączy spawanych odlewniczych stopów magnezu należących do grupy $\mathrm{Mg}-\mathrm{Al}-\mathrm{Zn}$.

W badaniach zastosowano dwie metody spawania łukowego w osłonie gazów obojętnych: elektrodą topliwą (MIG) i nietopliwą (TIG). Przedstawiono wyniki obserwacji wizualnych wykonywania złączy doczołowych, orazich ocenę makroskopową. W pracy skoncentrowano się na określeniu wpływu takich parametrów jak: rodzaj i natężenie prądu, napięcie łuku i prędkość spawania na wartość energii liniowej wykonywanych złączy oraz ich jakość (brak pęknięć gorących i porowatości).

\section{Abstract}

The paper presents results of an experimental studies of the influence of some arc welding parameters on weIdability of Mg-Al-Zn cast magnesium alloys. The metal inert gas (MIG) and tungsten inert gas (TIG) arc welding were chosen for the test. Results of visual inspection and macrostructure analysis of butt welds are presented. The main aim of the study was to assess the influence of polarity, welding speed, current and voltage on the shape of welds. It allowed to determine the value of necessary for linear energy input in order to obtain welded joints without hot cracking and porosity hazard.

\section{Wstęp}

Stopy magnezu, obok stopów aluminium i tytanu, wchodzą w skład grupy materiałów konstrukcyjnych nazywanych stopami lekkimi, które znajdują zastosowanie w przemyśle. Wynika to $z$ ich niskiej gęstości $\left(1,7 \div 1,8 \mathrm{~g} / \mathrm{cm}^{3}\right)$ - są lżejsze o $35 \%$ od aluminium $\left(2,7 \mathrm{~g} / \mathrm{cm}^{3}\right)$ i o $60 \%$ od tytanu $\left(4,4 \mathrm{~g} / \mathrm{cm}^{3}\right)$ oraz dobrych właściwości odlewniczych, m.in. lejności. Charakteryzują się wysoką sztywnością właściwą (stosunek modułu sprężystości do gęstości) i wytrzymałością właściwą (stosunek wytrzymałości do gęstości), zbliżoną do stopów tytanu i stali. Właściwości te wynikają z zastosowanych dodatków stopowych. Magnez

Dr inż. Lechosław Tuz - AGH Akademia Górniczo-Hutnicza w Krakowie, dr hab. inż. Andrzej Kolasa, prof. PW - Politechnika Warszawska. charakteryzuje się dobrą przewodnością cieplną, wysokim współczynnikiem tłumienia drgań i hałasu, dobrą podatnością na odlewanie, obróbkę plastyczną

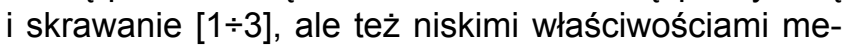
chanicznymi i odpornością korozyjną [4], wynikającą z jego wysokiego powinowactwa do tlenu oraz rozpuszczalności w wodzie [5]. Dodatki stopowe, takie jak aluminium, cynk, mangan, czy pierwiastki metali ziem rzadkich znacznie poprawiają te właściwości i umożliwiają zastosowanie części wykonanych ze stopów magnezu, w których istotnym parametrem jest waga konstrukcji [6].

Części maszyn wykonywane są najczęściej jako odlewy na gotowo w formach piaskowych przez odlewanie grawitacyjne (jednostkowe odlewy wielkogabarytowe dla przemysłu lotniczego, np. obudowy przekładni) lub ciśnieniowo (wielkoseryjne odlewy dla przemysłu motoryzacyjnego, np. obudowy silników, kierownice itp.). Stosowane są również metody 
odlewania kokilowego, precyzyjnego metodą wytapianych modeli lub odlewanie ze stanu półstałego metodami rheocasting i thixocasting [2]. Technologie te mogą spowodować występowanie się wad odlewniczych takich jak niedolania, rzadzizny i pęknięcia, które usuwane są metodami spawalniczymi: napawania i spawania, mogą być również wykorzystywane do łączenia prostych części w zespoły o złożonych kształtach. Widoczne jest zainteresowanie przemysłu elektronicznego stopami magnezu jako materiału umożliwiającego wykonywanie elementów cienkościennych, np. obudów laptopów lub telefonów komórkowych, mających nierzadko, skomplikowany kształt oraz tych, dla których wymagana jest wysoka jakość powierzchni ze względów estetycznych.

Dalszy rozwój zastosowań stopów magnezu uzależniony jest od możliwości naprawy odlewów i wykonywania technikami spajania połączeń o odpowiednich właściwościach mechanicznych, braku porowatości, pęknięć gorących i zimnych. Jednocześnie procesy te muszą gwarantować powtarzalność i być podatne na mechanizację i/lub automatyzację, co jest szczególnie istotne w produkcji wielkoseryjnej $[1,2,6]$. Niezbędne jest zatem określenie dla stopów magnezu spawalności rozumianej jako podatność do łączenia trwałego spełniającego określone wymagania użytkowe.

Spośród dostępnych technik spawania, metody takie jak spawanie elektrodą nietopliwą (TIG) i topliwą (MIG) znajdują zastosowanie w odlewniach, przy czym ze względu na znaczną ilość ciepła wprowadzanego do materiału nie zawsze mogą być one stosowane. Dlatego też prowadzone są badania również nad wykorzystaniem do wykonywania połączeń i naprawy odlewów spawalniczych źródeł o dużej koncentracji energii, takich jak: wiązka laserowa i badań zawężonym mechanicznie łukiem plazmowym. Jednocześnie ciągły rozwój stopu magnezu i urządzeń spawalniczych powoduje, że dotychczasowa wiedza w zakresie stosowania metod MIG i TIG nie zawsze znajduje odzwierciedlenie praktyczne, niedostatecznie został też poznany wpływ użycia nowoczesnych źródeł ciepła na możliwość naprawy i łączenia odlewów ze stopów magnezu.

W niniejszej pracy przedstawiono wpływ wybranych parametrów procesu spawania na kształt spoiny przy zastosowaniu spawania w osłonie gazów obojętnych elektrodą topliwą (MIG) i nietopliwą (TIG). Spośród analizowanych parametrów określono te, przy których uzyskano najlepsze właściwości oraz kształt złączy spawanych. Do próby spawania użyto dwóch stopów magnezu z grupy Mg-Al-Zn.

\section{Materiały do badań}

Materiałami użytymi do badań są stopy magnezu w stanie lanym o składzie chemicznym przedstawionym w tablicy I. Do wykonania złączy użyto płaskowników o grubości $3 \mathrm{~mm}$, wykonując połączenia wzdłuż
Tablica I. Skład chemiczny stopów magnezu: AM-Lite i AZ91 (\% wag.)

Table I. Chemical composition of AM-Lite and AZ91 alloys (\% mas.)

\begin{tabular}{|c|c|c|c|c|}
\hline \multirow{2}{*}{$\begin{array}{c}\text { Oznaczenie } \\
\text { stopu }\end{array}$} & \multicolumn{4}{|c|}{ Pierwiastek stopowy } \\
\cline { 2 - 5 } & $\mathrm{Al}$ & $\mathrm{Zn}$ & $\mathrm{Mn}$ & $\mathrm{Mg}$ \\
\hline AM-Lite & 2,2 & 16,6 & 0,31 & reszta \\
\hline AZ91 & 9,0 & 0,7 & 0,17 & reszta \\
\hline
\end{tabular}

Tablica II. Skład chemiczny drutu elektrodowego AZ61 (\% wag.) Table II. Chemical composition of electrode wire AZ61 (\% mas.)

\begin{tabular}{|c|c|c|c|c|c|c|c|c|}
\hline $\mathrm{Si}$ & $\mathrm{Fe}$ & $\mathrm{Cu}$ & $\mathrm{Mn}$ & $\mathrm{Zn}$ & $\mathrm{Ni}$ & $\mathrm{Inne}$ & $\mathrm{Al}$ & $\mathrm{Mg}$ \\
\hline 0,01 & 0,001 & 0,002 & 0,2 & 0,53 & 0,001 & $\max .0,3$ & 5,89 & reszta \\
\hline
\end{tabular}

najdłuższej krawędzi. Ponieważ zastosowane w badaniach metody są używane do łączenia lub naprawy odlewów, nie wykonano obróbki cieplnej próbek w celu ujednolicenia struktury bądź poprawy właściwości mechanicznych. Ujawniona struktura stosowanych stopów jest typową rozdrobnioną strukturą odlewniczą z niezauważalną kierunkowością krystalitów. Analiza struktury wykazała, że składa się ona z krystalitów roztworu stałego $\alpha-M g$ oraz eutektyki będącej mieszaniną faz $\alpha-\mathrm{Mg}$ i $\mathrm{Mg}_{17} \mathrm{Al}_{12}$ oraz wydzieleń globularnych $\mathrm{Al}_{8} \mathrm{Mn}_{5}[7 \div 10]$. W drugim stopie, ze względu na znacznie większą zawartość cynku, obserwowana jest również eutektyka z wydzieleniami krystalitów fazy międzykrystalicznej $\mathrm{Mg}_{7} \mathrm{Zn}_{3}$.

Do wykonania złączy metodą MIG stosowano materiał dodatkowy w postaci drutu litego o średnicy 1,6 mm i składzie chemicznym podanym w tablicy II. W metodzie TIG nie stosowano materiału dodatkowego.

\section{Metodyka badań}

Badaniom poddano doczołowe złącza spawane metodami: elektrodą topliwą w osłonie gazów obojętnych (MIG) oraz elektrodą nietopliwą w osłonie gazów obojętnych (TIG).

Proces spawania łukowego prowadzono przy zastosowaniu manipulatora liniowego, uzyskując $w$ ten sposób powtarzalność wyników. Stosowano gazy i mieszaniny gazów obojętnych chemicznie podawanych od strony lica spoiny. Spawanie metodą TIG prowadzono prądem przemiennym (AC) z podgrzewaniem wstępnym do $130^{\circ} \mathrm{C}$ dla $\mathrm{AZ91}$ i $170^{\circ} \mathrm{C}$ dla AM-Lite w celu uniknięcia pęknięć gorących zauważonych we wcześniejszych próbach [10]. Spawanie MIG prowadzono prądem stałym (DC+), łukiem zwarciowym, stosując $7 \mathrm{~mm}$ wolny wylot elektrody oraz prędkość podawania drutu $1,6 \mathrm{~m} / \mathrm{min}$. Pozostałe parametry procesu i wyznaczone wartości energii liniowych dla obydwu metod podano w tablicy III. Do wykonania złączy doczołowych metodą MIG zastosowano odstęp między łączonymi brzegami o szerokości $1,5 \mathrm{~mm}$; 
Tablica III. Parametry spawania

Table III. Process parameters

\begin{tabular}{|c|c|c|c|}
\hline Parametr & Jednostka & MIG & TIG \\
\hline Prędkość spawania & $\mathrm{mm} / \mathrm{min}$ & 400 & 270 \\
\hline Natężenie prądu & $\mathrm{A}$ & 73 & 90 \\
\hline Napięcie łuku & $\mathrm{V}$ & 17,4 & 13 \\
\hline $\begin{array}{c}\text { Rodzaj i wydatek } \\
\text { gazu osłonowego }\end{array}$ & $\mathrm{I} / \mathrm{min}$ & $\begin{array}{c}\text { mieszanina argon } 50 \% \\
- \text { hel } 50 \%-16\end{array}$ & hel - 16 \\
\hline Energia liniowa & $\mathrm{kJ} / \mathrm{m}$ & 124 & 151 \\
\hline
\end{tabular}

w metodzie TIG brzegi łączonych materiałów były dociśnięte do siebie.

Dobór parametrów procesu oraz ocenę ich wpływu na jakość złączy przeprowadzono bezpośrednio po ich wykonaniu - na tej podstawie podejmowano decyzje o zmianie stosowanych parametrów oraz wytypowano parametry, przy których uzyskiwano pełne przetopienia oraz poprawny kształt lica i grani spoiny. Wytypowane w ten sposób złącza poddano badaniom metalograficznym makrostruktury, przeprowadzając ocenę jakości uzyskanego złącza [10]. Jako kryteria jakości złącza przyjęto brak pustek, porowatości i pęknięć gorących. Ze względu na brak norm dotyczących jakości złączy ze stopów magnezu dokonano również oceny kształtu uzyskanych spoin.

Ocenę makrostruktury przeprowadzono na zgładach metalograficznych wykonanych w płaszczyźnie prostopadłej do kierunku spawania przy zastosowaniu mikroskopu świetlnego. Zgłady trawiono 3,5\% roztworem Nitalu.

\section{Parametry procesu}

W badanych metodach spawania łukowego analizowano wpływ prędkości spawania oraz napięcia łuku w metodzie MIG i natężenia prądu w metodzie TIG na kształt spoiny.

Biegunowość prądu spawania. Na powierzchni stopów magnezu zalega trudnotopliwa warstewka tlenków magnezu o temperaturze topnienia ok. $2500^{\circ} \mathrm{C}$. Jej obecność ma negatywny wpływ na przebieg procesu spawania zarówno metodą TIG, jak i MIG, ponieważ tlenki te pogarszają zwilżanie brzegów przez ciekły metal, utrudniając uzyskanie trwałego połączenia. Niezbędne jest czyszczenie katodowe, które stosuje się w przypadku biegunowości dodatniej na elektrodzie. Wówczas tlenki te ulegają rozbiciu przez jony gazu osłonowego, odsłaniając czystą powierzchnię metalu. Zjawisko to zapobiega również obecności tlenków w spoinie, co mogłoby się przyczynić do inicjacji i rozwoju pęknięć. Podczas spawania metodą MIG zastosowano prąd stały o biegunowości dodatniej na elektrodzie, co również powodowało szybsze stapianie drutu elektrodowego. Podczas spawania elektrodą nietopliwą (TIG) zastosowano prąd przemienny. Nie zaobserwowano przy tym utraty stabilności jarzenia się łuku spawalniczego przy prądzie przemiennym - dzięki użyciu źródła prądu wyposażonego w jonizator. Stosowanie biegunowości dodatniej w przypadku złączy MIG przyczyniło się w znacznym stopniu do powstania wypukłego lica spoiny. W metodzie TIG, nie używając spoiwa, uzyskano zbliżone grubości złączy i materiału rodzimego.

Prędkość spawania. W wykonanych próbach prędkość spawania wpływała na ilość stopionego metalu. Przy największych prędkościach obserwowano brak przetopienia po stronie grani spoiny w przypadku spawania łukowego zarówno metodą MIG, jak i TIG. Był widoczny również znacznie mniejszy nadlew lica spoiny $w$ przypadku spawania MIG oraz zapadnięte lico w metodzie TIG. Spoina była również węższa. Znaczne zmniejszenie prędkości spawania w metodzie TIG było przyczyną braku połączenia wskutek usuwania ciekłego metalu z jeziorka spawalniczego $(150 \mathrm{~mm} / \mathrm{min}$ przy $90 \mathrm{~A})$. W metodzie MIG natomiast obserwowano nadmierny rozprysk metalu oraz duży nadlew lica spoiny $(350 \mathrm{~mm} / \mathrm{min}$ przy $17,4 \mathrm{~V}$ i $73 \mathrm{~A}$ ). Zwiększenie $\mathrm{w}$ tym wypadku wolnego wylotu elektrody do $15 \mathrm{~mm}$ spowodowało zwiększenie rozprysku, nazywanego potocznie zjawiskiem strzelania łuku. Przy parametrach przedstawionych w tablicy III obserwowano również duży nadlew lica spoiny i wypływ metalu po stronie grani, przy czym kształt i wymiary spoin wskazują, że zmiana prędkości spawania nie wpływa znacząco na ich kształty i wymiary (rys. 1).

Natężenie prądu - metoda TIG. Wzrost natężenia prądu wpływał na głębokość wtopienia oraz na szerokość spoiny. Zbyt małe natężenie prądu powodowało tylko nadtopienie brzegów, nie powodując wymieszania materiału. Próby przetapiania wykazały, że zastosowanie prądu o natężeniu mniejszym niż $60 \mathrm{~A}$ nie powoduje pełnego przetopienia próbki $(3 \mathrm{~mm})$. Przy natężeniu prądu powyżej $70 \mathrm{~A}$ nastąpił jednak pełen przetop w złączach. Wartość natężenia prądu powyżej $110 \mathrm{~A}$ powodowała powstawanie pęknięć gorących mimo podgrzewania wstępnego. Prawdopodobnie było to wynikiem przekraczania temperatury

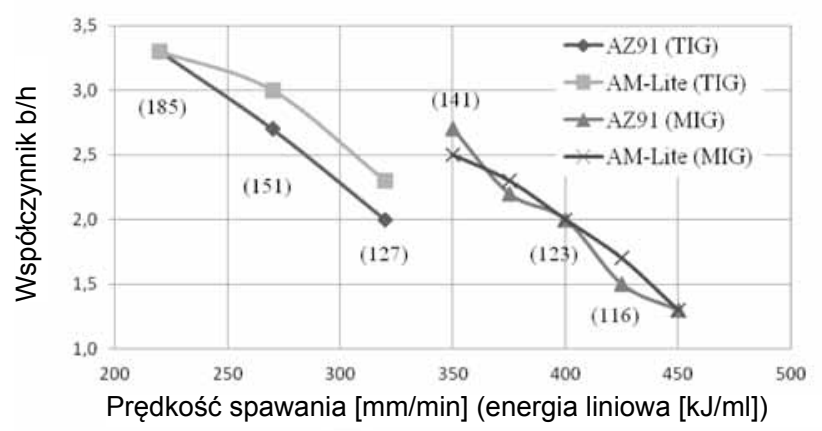

Rys. 1. Wpływ prędkości spawania na kształt spoiny: b - szerokość spoiny, $\mathrm{h}$ - głębokość wtopienia; w nawiasach energia liniowa: TIG $-\mathrm{I}=90 \mathrm{~A}, \mathrm{U}=13 \mathrm{~V}, \eta=60 \%, \mathrm{k}=0,97$; MIG $-\mathrm{I}=73 \mathrm{~A}$, $\mathrm{U}=17,4 \mathrm{~V}, \eta=65 \%$

Fig. 1. Welding speed impact on weld shape: $b$ - weld width, $\mathrm{h}$ - fusion depth, in brackets heat input for: $\mathrm{TIG}-\mathrm{I}=90 \mathrm{~A}, \mathrm{U}=13 \mathrm{~V}$, $\eta=60 \%, k=0,97 ; M I G-I=73 \mathrm{~A}, \mathrm{U}=17,4 \mathrm{~V}, \eta=65 \%$ 
początku zakresu kruchości wysokotemperaturowej i obecności segregujących dodatków stopowych, a sam proces spawania dostarczał do materiału zbyt dużą ilość ciepła. Zauważono, że dla badanych stopów temperatura podgrzewania wstępnego była różna i wynosiła odpowiednio $130^{\circ} \mathrm{C}$ (AZ91) i $170^{\circ} \mathrm{C}$ (AMLite). Brak podgrzewania wstępnego powodował występowanie pęknięć gorących obserwowanych bezpośrednio po spawaniu. Pęknięcia przebiegały od końca spoiny do jej początku. Natężenie prądu w przedziale $70 \div 110$ A umożliwiało wykonywanie złączy spawanych, przy czym w przypadku mniejszych wartości natężenia uzyskiwano niepełny przetop i węższe lico spoiny (rys. 3). Przykładowe złącza TIG uzyskane przy tych parametrach procesu przedstawiono na rysunku 2.

Napięcie łuku - metoda MIG. Napięcie łuku spawalniczego zależy m.in. od rodzaju gazu osłonowego oraz od długości łuku spawalniczego. W przeprowadzanych próbach oba parametry były niezmienne (tabl. III), natomiast napięcie zmieniono na źródle zasilania

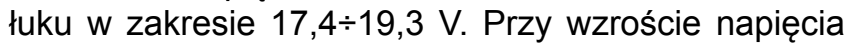
obserwowano wzrost ilości rozprysków i szerokości spoiny. Przy małych wartościach napięcia $(17,4 \mathrm{~V})$ widoczne było pełne przetopienie łączonych brzegów i wypełnienie całej szczeliny przez spoiwo. Wzrost napięcia powodował głębsze wtopienie (lepsze stopienie) brzegów, ale też powstawanie pęknięć przebiegających wzdłuż spoiny. Pełne przetopienie oraz brak pęknięć gorących uzyskano dla parametrów podanych

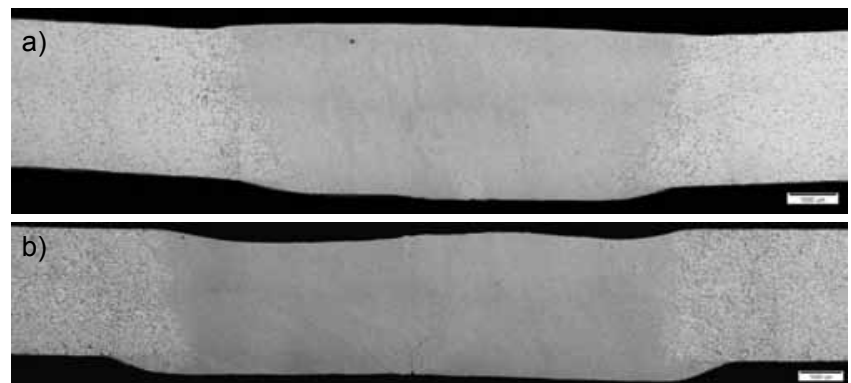

Rys. 2. Makrostruktura złączy spawanych metodą TIG: a) AZ91, $70 \mathrm{~A}, 0,27 \mathrm{~m} / \mathrm{min}, 130^{\circ} \mathrm{C}$; b) AM-Lite, $80 \mathrm{~A}, 0,27 \mathrm{~m} / \mathrm{min}, 170^{\circ} \mathrm{C}$

Fig. 2. Macrostructure of TIG welded joint: a) AZ91, $70 \mathrm{~A}$, $0,27 \mathrm{~m} / \mathrm{min}, 130^{\circ} \mathrm{C}$; b) AM-Lite, $80 \mathrm{~A}, 0,27 \mathrm{~m} / \mathrm{min}, 170^{\circ} \mathrm{C}$

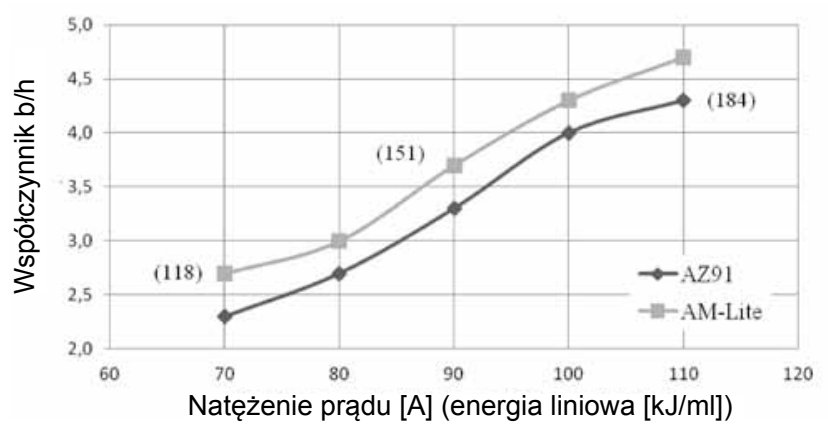

Rys. 3. Wpływ natężenia prądu na kształt spoiny: b - szerokość spoiny, $\mathrm{h}$ - głębokość wtopienia; $\mathrm{w}$ nawiasach energia liniowa: $\mathrm{v}=0,27 \mathrm{~m} / \mathrm{min}, \mathrm{U}=13 \mathrm{~V}, \mathrm{\eta}=60 \%, \mathrm{k}=0,97$

Fig. 3. Current impact on weld shape: $b-$ weld width, $h-$ fusion depth, in brackets heat input for: $v=0,27 \mathrm{~m} / \mathrm{min}, \mathrm{U}=13 \mathrm{~V}$, $\eta=60 \%, k=0,97$
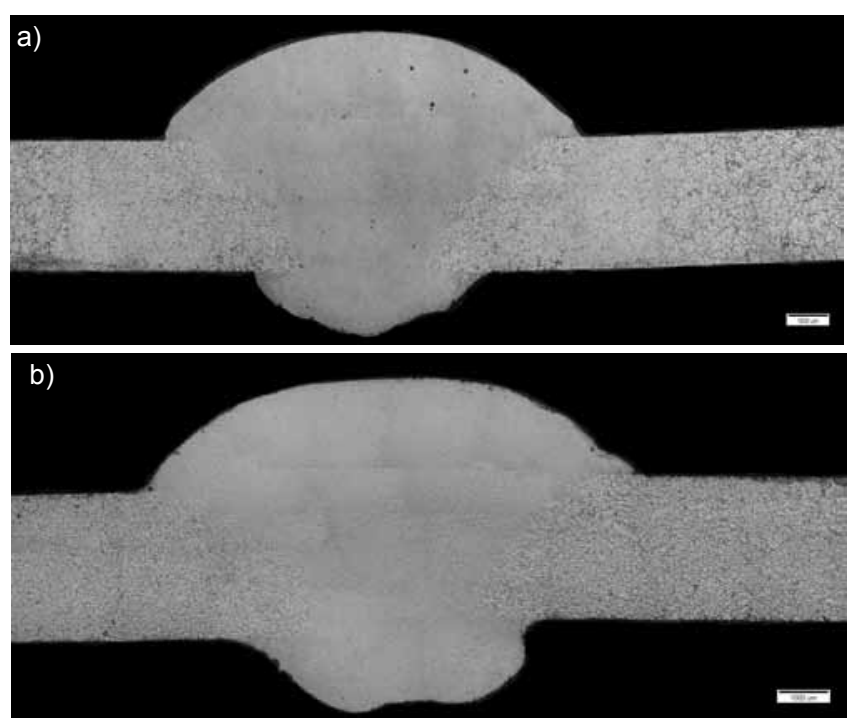

Rys. 4. Makrostruktura złączy spawanych metodą MIG, materiał dodatkowy AZ61: a) AZ91, 73 A, 17,4 V, 0,4 m/min; b) AM-Lite, $73 \mathrm{~A}$, $17,4 \mathrm{~V}, 0,4 \mathrm{~m} / \mathrm{min}$

Fig. 4. Macrostructure of MIG welded joint, filler metal $A Z 61$ : a) AZ91, $73 \mathrm{~A}, 17,4 \mathrm{~V}, 0,4 \mathrm{~m} / \mathrm{min}$; b) AM-Lite, $73 \mathrm{~A}, 17,4 \mathrm{~V}, 0,4 \mathrm{~m} / \mathrm{min}$

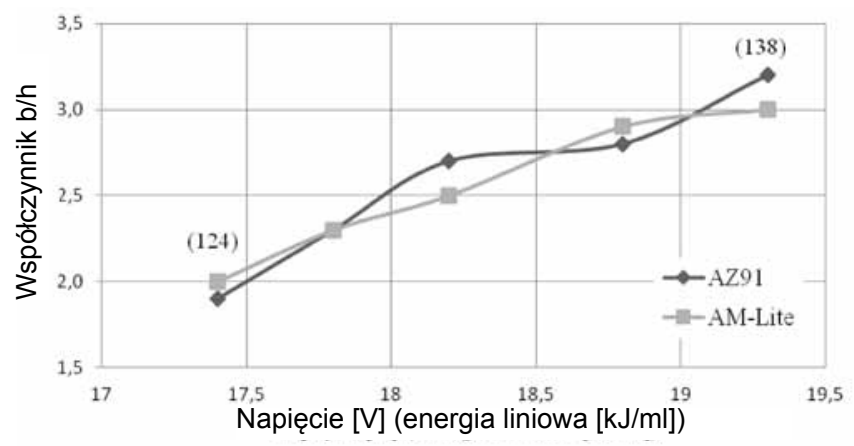

Rys. 5. Wpływ napięcia łuku na kształt spoiny: $b$ - szerokość spoiny, $\mathrm{h}$ - głębokość wtopienia; w nawiasach energia liniowa: I = $73 \mathrm{~A}$, $v=0,4 \mathrm{~m} / \mathrm{min}, \eta=65 \%$

Fig. 5. Voltage impact on weld shape: $\mathrm{b}-$ weld width, $\mathrm{h}-$ fusion depth, in brackets heat input for: $\mathrm{I}=73 \mathrm{~A}, \mathrm{v}=0,4 \mathrm{~m} / \mathrm{min}, \eta=65 \%$

w tablicy III. Przykładowe złącza wykonane przy tych parametrach przedstawiono na rysunku 4. Na rysunku 5 pokazano natomiast wpływ napięcia łuku na kształt spoiny.

\section{Makrostruktura złączy}

Na rysunkach 2 i 4 przedstawiono makrostrukturę złączy wykonanych metodami TIG i MIG. Uzyskane złącza różnią się wielkością, co jest skutkiem zastosowanej metody spawania. Najszersze złącze uzyskano dla metody TIG - szerokość wynosiła ok. $10 \mathrm{~mm}$. W przypadku obu badanych stopów zaobserwowano występowanie trzech charakterystycznych dla złączy spawanych obszarów: spoiny, strefy wpływu ciepła i materiału rodzimego. Obserwacja linii wtopienia wskazuje na jej nierówny, rozbudowany kształt. Złącza charakteryzują 
się symetrią względem osi spoiny, ale linie wtopienia nie są równoległe, co może wskazywać na odmienne właściwości mechaniczne złączy po stronie lica i grani. Złącze wykonane metodą MIG, pomimo zastosowania przerwy technologicznej o szerokości 1,5 mm, charakteryzuje się wypukłym licem oraz wypływem po stronie grani. Złącza spawane metodą TIG charakteryzują się nieznacznym obniżeniem lica spoiny wynikającym z zapadania się materiału podczas spawania.

Złącza wykonane metodą TIG mają regularny, symetryczny kształt $z$ widoczną SWC o szerokości dochodzącej do $3 \mathrm{~mm}$ (rys. 2), ale linia wtopienia ma nieregularny, rozbudowany kształt o szerokości do $1 \mathrm{~mm}$. Szerokość spoin wynosi 9 $\div 10 \mathrm{~mm}$ dla sto-

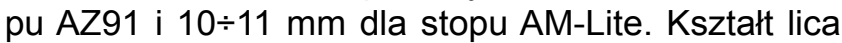
i grani jest właściwy, przy czym dla stopu AM-Lite obserwowano tendencję do nieznacznego zapadania się lica spoiny.

We wskazanych metodach spajania przy zastosowanej metodyce badań nie zaobserwowano pęknięć gorących, natomiast zauważono śladowe ilości porów i pustek.

\section{Podsumowanie}

Przeprowadzone próby łączenia stopów magnezu z grupy Mg-Al-Zn wykazały, że możliwe jest wykonanie połączeń spawanych metodą TIG i MIG wolnych od wad spawalniczych (zimnych i gorących pęknięć, porów). Niezbędne jest natomiast zachowanie szczególnych warunków wykonywania połączeń, takich jak stabilne zamocowanie łączonych elementów i dobre przyleganie łączonych brzegów oraz ochrona jeziorka spawalniczymi gazami osłonowymi - helem w TIG oraz mieszaniną helu i argonu w MIG. Istotne jest również wstępne podgrzewanie płaskowników w celu uniknięcia pęknięć.

Wielkość złączy oraz ich kształt różnią się w zależności od zastosowanych metod łączenia i parametrów procesu, ale mają regularny, symetryczny kształt o stosunkowo wąskiej SWC.

\section{Literatura}

[1] Kulekci M.K.: Magnesium and its alloys in applications in automotive industry, Journal of Advanced Manufacturing Technology, 2008, 39: 851-865.

[2] Friedrich F., Schuman S.: Research for a „New age of magnesium" in the automotive industry, Journal of Materials Processing Technology, 2001, 117: 276-281.

[3] Cao X., Jahazi M., Immarigeon J.P., Wallace W.: A review of laser welding techniques for magnesium alloys, Journal of Materials Processing Technology, 2006, 171: 188-204.

[4] Abdel Aal A.: Protective coating for magnesium alloy, Journal of Materials and Science, 2008, 43: 2947-2954.

[5] Avedesian M.M., Baker H.: Magnesium and magnesium alloys, ASM Specialty Handbook 1999.

[6] Vesling F., Ryspaev T.: Effect of heat treatment on the superplasticity of magnesium alloys, Russian Journal of Non-Forrous Metals, 2007, 48: 57-62.
[7] Peng L., Yajiang L., Haoran G., Juan W.: Microstructure characteristics in TIG welded joint of $\mathrm{Mg} / \mathrm{Al}$ dissimilar materials, Materials Letters, 2007, 61: 1288-1291.

[8] Tuz L., Kołodziejczak P., Kolasa A.: Struktura złączy stopów AZ91 i AM-Lite wykonanych metodą TIG, Przegląd Spawalnictwa, 12/2010, s. 41-43.

[9] Tuz L., Kolasa A., Pfeifer T.: Struktura doczołowych złączy ze stopów magnezu otrzymanych metodą MIG, Przegląd Spawalnictwa, 12/2011, s. 36-42.

[10] Tuz L.: Badania właściwości złączy ze stopów magnezu wykonanych wybranymi technikami łączenia, Rozprawa doktorska, Warszawa 2011.

\section{Podziękowania}

Materiał do badań został udostępniony przez: dr. Christiana Kettlera, Advanced Magnesium Technologies, Australia i Polmag Sp. z o.o., Polska. Praca współfinansowana przez Ministerstwo Nauki i Szkolnictwa Wyższego w ramach środków budżetowych na naukę w latach 2010-2011 jako projekt badawczy nr N N508 582739 i pracę statutową 11.11.110.156. 